\title{
AVALIAÇÃO DE GRAMÍNEAS FORRAGEIRAS NA REGIÃO SUL DE MINAS GERAIS ${ }^{1}$
}

\author{
MILTON DE ANDRADE BOTREL루 MAURÍLIO JOSÉ ALVIM e DEISE FERREIRA XAVIER ${ }^{4}$
}

\begin{abstract}
RESUMO - Foram conduzidos dois experimentos na região do sul de Minas Gerais para avaliar o potencial de gramíneas forrageiras. No experimento 1 foram avaliadas as seguintes espécies, consideradas de baixa exigência nutricional: Andropogon gayanus, Kunt; Brachiaria brizantha, Stapf; Brachiaria decumbens, Stapf; Brachiaria ruziziensis, Germain Evrard; Brachiaria humidicola (Rendle) Schweickt e Melinis minutiflora, Beauv. No experimento 2 foram avaliadas as gramíneas consideradas de média e alta exigência nutricional, a saber: Setaria sphacelata (Schum.) Moss; Hemarthria altissima (Poir.) Stapf; Chloris gayana, Kunt; Cynodon nlemfuensis, Vanderyst var. nlemfuensis; Hyparrhenia rufa, (Ness) Stapf. e as cultivares de Panicum maximum, Jacq.: Tobiatã, Green Panic e Makueni. O delineamento experimental foi de blocos ao acaso com três repetições. Os níveis de calagem e de adubação para estabelecimento e manutenção foram diferenciados para os dois experimentos. Cada espécie foi avaliada nos seguintes aspectos: produção de forragem e teor de proteína bruta no período da seca e das chuvas e cobertura vegetal do solo. As gramíneas do experimento 1 que se destacaram na maioria dos aspectos avaliados foram: $B$. brizantha, $B$. decumbens, A. gayanus enquanto que no experimento 2 as espécies que apresentaram maior potencial forrageiro foram: $S$. sphacelata, P. maximum cv. Tobiatã.
\end{abstract}

Termos para indexação: produção de forragem, qualidade de forragem, cobertura do solo.

\section{EVALUATION OF FORAGE GRASSES FOR THE SOUTH REGION OF MINAS GERAIS}

\begin{abstract}
Two experiments were undertaken in the South region of Minas Gerais State, Brazil, to evaluate the yield potential of forage grasses. In experiment 1 , the following species, considered as having low nutritional requirements, were evaluated: Andropogon gayanus, Kunt; Brachiaria brizantha, Stapf; Brachiaria decumbens, Stapf; Brachiaria ruziziensis, Germain Evrard; Brachiaria humidicola (Rendle) Schweickt and Melinis minutiflora, Beauv. In experiment 2, the species considered as having medium and high nutritional requirements, that is: Setaria sphacelata (Schum.); Hemarthria altissima, (Poir.) Stapf; Chloris gayana, Kunt; Cynodon nlemfuensis, Vanderyst var. nlemfuensis; Hyparrhenia rufa, (Ness) and the cultivars Panicum maximum, Jacq.: Tobiatã, Green Panic and Makueni were evaluated. The experimental design used was randomized blocks with three replications. Rates of lime and of fertilizers for both establishment and maintenance differed between experiments. Each grass was evaluated for the following atributes: forage yield and crude protein content in the dry and wet season and ground cover. In experiment 1 , the grasses with outstanding performance were B. brizantha, $B$. decumbens and A. gayanus, while in experiment 2 the species having the highest forage yield potential were: S. sphacelata, P. maximum cv. Tobiatã.
\end{abstract}

Index terms: forage yield, forage quality, ground cover.

\section{INTRODUÇÃO}

O Estado de Minas Gerais contribui com 30\% do leite produzido no País, e a Mesorregião

\footnotetext{
${ }^{1}$ Aceito para publicação em 14 de julho de 1998.

${ }^{2}$ Eng. Agr., M.Sc., Embrapa-Centro Nacional de Pesquisa de Gado de Leite (CNPGL), Rua Eugênio do Nascimento, 610, CEP36038-330 Juiz de Fora, MG.E-mail: mbotrel@cnpgl.embrapa.br ${ }^{3}$ Biólogo, M.Sc., Embrapa-CNPGL.

${ }^{4}$ Eng $\underline{a}$ Agr ${ }^{2}$, M.Sc., Embrapa-CNPGL.
}

Sul/Sudeste de Minas participa com, aproximadamente, $20 \%$ do leite produzido no Estado (Zoccal, 1994). Entretanto, a produtividade média de leite alcançada nessa região é baixa, em relação às obtidas em outros países tropicais como Austrália, Nova Zelândia, Porto Rico e Cuba ( Martinez, 1981; Assis, 1982), estando isto certamente relacionado com a baixa qualidade e capacidade de suporte das pastagens predominantes na região (Pereira \& Fonseca, 1990). 
O elevado potencial das pastagens tropicais na alimentação de vacas em lactação é evidenciado por meio da revisão da literatura, efetuada por Stobbs (1976) e Vicente-Chandler et al. (1983). Essas pastagens, quando bem manejadas, podem constituir a principal fonte de nutrientes para vacas mestiças leiteiras. Essa situação é, segundo Assis (1986), mais evidente nos trópicos, onde extensas áreas ainda estão disponíveis para a produção animal. Entretanto, para que o potencial dessas pastagens se manifeste, é necessário que se utilizem espécies forrageiras adaptadas às condições edafoclimáticas locais. $\mathrm{O}$ uso indevido de forrageiras não adaptadas poderá trazer efeitos negativos, não só do ponto de vista econômico, mas também ecológico. Esses efeitos se manifestam quando da substituição do pasto por espécies indesejáveis, sem valor forrageiro, ou pelo aparecimento, em regiões montanhosas, de áreas erodidas. O resultado final é a perda irreversível da camada superficial do solo e diminuição da capacidade de suporte da pastagem.

Esse trabalho teve como objetivo avaliar gramíneas forrageiras nas condições de solo e clima da região Sul de Minas Gerais.

\section{MATERIAL E MÉTODOS}

Foram conduzidos dois experimentos (1 e 2), na Fazenda Experimental da Empresa de Pesquisa Agropecuária de Minas Gerais, localizada no município de Cambuquira, sul do Estado de Minas Gerais. Os experimentos foram instalados em um Latossolo Vermelho-Amarelo, de baixa fertilidade natural, representativo da região, e cuja característica química é mostrada a seguir: $\mathrm{pH}$ em água $=4,9$; $\mathrm{Al}=0,81 \mathrm{cmol}_{\mathrm{c}} / \mathrm{dm}^{3} ; \mathrm{Ca}+\mathrm{Mg}=1,09 \mathrm{cmol}_{\mathrm{c}} / \mathrm{dm}^{3}$; $\mathrm{K}=0,13 \mathrm{cmol}_{\mathrm{d}} / \mathrm{dm}^{3} ; \mathrm{P}=6,8 \mathrm{mg} / \mathrm{dm}^{3}$ e $\mathrm{MO}=2,46 \mathrm{dag} / \mathrm{kg}$. O clima da região é do tipo Cwa, mesotérmico, com verão quente e chuvoso e inverno frio e seco. Na Tabela 1, são apresentados os dados médios de precipitação e temperatura ocorridos durante o período de condução dos experimentos.

As gramíneas avaliadas foram reunidas em dois grupos, de acordo com a maior ou menor exigência nutricional, e cada grupo constituiu um experimento distinto.

No primeiro experimento, foram avaliadas as seguintes espécies, consideradas de menor exigência nutricional: Brachiaria decumbens, Brachiaria ruziziensis, Brachiaria brizantha cv. Marandu, Brachiaria humidicola, Andropogon gayanus cv. Planaltina e Melinis minutiflora.
Os tratamentos do segundo experimento, foram constituídos das seguintes gramíneas, consideradas de média e alta exigência nutricional: Panicum maximum cv. Green Panic, Panicum maximum cv. Makueni, Panicum maximum cv. Tobiatã, Setaria sphacelata cv. Kazungula, Hemarthria altissima, Cynodon nlemfuensis, Chloris gayana e Hyparrhenia rufa.

A calagem e as adubações para estabelecimento e manutenção foram diferenciadas nos dois experimentos. A calagem foi realizada somente na área destinada ao experimento 2, 60 dias antes do plantio, e numa dosagem equivalente a 2 t/ha de calcário dolomítico. A adubação para estabelecimento foi realizada por ocasião do plantio, e baseou-se na dosagem de 50 e $80 \mathrm{~kg} / \mathrm{ha}$ de $\mathrm{P}_{2} \mathrm{O}_{5}$ (superfosfato simples) e 0 , e $50 \mathrm{~kg} / \mathrm{ha}$ de $\mathrm{K}_{2} \mathrm{O}$ (cloreto de potássio), respectivamente nos experimentos 1 e 2 . Dois meses após o plantio, foi constatada deficiência generalizada de $\mathrm{N}$ nas gramíneas do experimento 2, sendo então aplicado em cobertura $50 \mathrm{~kg} / \mathrm{ha}$ de $\mathrm{N}$ ( sulfato de amônio). A adubação de manutenção foi feita anualmente, parcelada em duas aplicações durante o período das chuvas, nas dosagens de 50 e $100 \mathrm{~kg} / \mathrm{ha}$ de $\mathrm{N}$ (sulfato de amônio) e 60 e $60 \mathrm{~kg} / \mathrm{ha}$ de $\mathrm{K}_{2} \mathrm{O}$ (cloreto de potássio), respectivamente, para os experimentos 1 e 2 . O plantio foi a lanço, incorporando-se as sementes ao solo com o uso de ancinhos, exceto para a $H$. altissima e $C$.nlemfuensis, que foi realizado em sulcos, usando-se mudas.

O delineamento experimental foi o de blocos ao acaso, em três repetições, com parcelas de $5 \times 4 \mathrm{~m}$. Os cortes utilizados nas avaliações foram feitos a uma altura de $10 \mathrm{e}$

TABELA 1. Dados médios de precipitação, temperatura máxima e mínima referente ao período de condução do experimento.

\begin{tabular}{lccc}
\hline Mês & $\begin{array}{c}\text { Precipitação } \\
(\mathrm{mm})\end{array}$ & \multicolumn{2}{c}{ Temperatura $\left({ }^{\circ} \mathrm{C}\right)$} \\
\cline { 3 - 4 } & & Máxima & Mínima \\
\hline Janeiro & 233,0 & 28,0 & 18,4 \\
Fevereiro & 261,0 & 27,3 & 18,1 \\
Março & 131,4 & 27,7 & 17,0 \\
Abril & 79,9 & 26,4 & 16,4 \\
Maio & 80,2 & 24,3 & 14,2 \\
Junho & 20,5 & 22,2 & 10,3 \\
Julho & 16,4 & 22,6 & 9,6 \\
Agosto & 32,8 & 25,0 & 11,2 \\
Setembro & 68,1 & 26,0 & 13,7 \\
Outubro & 71,9 & 27,0 & 15,4 \\
Novembro & 142,0 & 21,1 & 16,4 \\
Dezembro & 378,1 & 26,7 & 17,5 \\
\hline
\end{tabular}


$30 \mathrm{~cm}$, nas gramíneas de crescimento prostrado e cespitoso, respectivamente. Durante o período das chuvas, os cortes foram realizados sempre que a maioria das gramíneas prostradas e eretas atingiam, respectivamente, a altura de $30 \mathrm{e}$ $60 \mathrm{~cm}$, e no período da seca, quando atingiam 20 e $40 \mathrm{~cm}$. Esse manejo permitiu um intervalo entre cortes de 60 dias, em média, no período da seca, e de 35 dias no período das águas.

O primeiro ano após o plantio foi considerado para estabelecimento, e todos os tratamentos foram manejados para aumentar e uniformizar a população de plantas. Em novembro de 1986, após um corte de uniformização em toda a área experimental, cada gramínea foi avaliada quanto a produção de matéria seca (MS), porcentagem de proteína bruta $(\mathrm{PB})$ e cobertura vegetal do solo.

A estimativa da produção de forragem (matéria seca a $65^{\circ} \mathrm{C}$ ) foi feita por meio de cortes da forragem existente em um quadrado de um metro de lado, lançado aleatoriamente, três vezes em cada parcela. A forragem verde colhida foi pesada para cálculo da produção, da qual retirava-se uma amostra representativa para secagem durante 48 horas e posteriores determinações de MS e $\mathrm{PB}$, segundo a Association of Official Agriculture Chemists (1970).

A porcentagem da cobertura vegetal do solo foi feita durante o período das chuvas, após a fase de estabelecimento dos experimentos. A metodologia utilizada nessa avaliação foi o método dos pontos, proposto por Brown (1954).

Os dados obtidos foram submetidos à análise de variância, e o teste de Tukey foi aplicado a 5\% de probabilidade para contraste entre médias.

\section{RESULTADOS E DISCUSSÃO}

\section{Produção de matéria seca}

Experimento 1 - As espécies $B$. brizantha, $B$. decumbens e A. gayanus foram as mais produtivas $(\mathrm{P}<0,05)$ durante o período da seca, apresentando produções em torno de $3.000 \mathrm{~kg} / \mathrm{ha}$ de $\mathrm{MS}$. As demais espécies apresentaram produções semelhantes $(\mathrm{P}>0,05)$, com valor médio de $423 \mathrm{~kg} / \mathrm{ha}$ de MS (Tabela 2).

Durante a estação das chuvas, a $B$. brizantha se destacou pelo maior potencial para produção de forragem $(13.091 \mathrm{~kg} / \mathrm{ha}$ de MS). A produção da B. decumbens, nessa época do ano, foi de $11.425 \mathrm{~kg} / \mathrm{ha}$ de MS, sendo significativamente inferior à produ- ção da B. brizantha e superior aos rendimentos alcançados pelas demais espécies.

A $B$. brizantha foi a espécie que apresentou a maior $(\mathrm{P}<0,05)$ produção anual de forragem (16.379 kg/ha de MS). Por outro lado, as gramíneas B. ruziziensis e Melinis minutiflora (capim-gordura), espécie naturalizada na região, foram as menos produtivas, sendo o rendimento anual dessas espécies, em média, três vezes inferior ao da $B$. brizantha (Tabela 2) .Esses resultados podem explicar a substituição, em grandes áreas do território nacional, do capim-gordura por outras espécies mais produtivas, e explicam também a baixa expansão das áreas de plantio da B. ruzizienses, mesmo sendo essa gramínea uma das braquiárias mais palatáveis (Vieira, 1994).

A melhor distribuição estacional da produção de forragem foi alcançada com as espécies A. gayanus, $B$. brizantha e $B$. decumbens, ou seja: essas forrageiras concentraram, em média, $21 \%$ da produção anual no período da seca, enquanto que nas demais espécies essa distribuição variou de $4 \%$ (B. humidicola) a $8 \%$ (capim-gordura).

O baixo potencial forrageiro observado durante o período da seca com a $B$. humidicola e $B$. ruziziensis também foi observado por Alvim et al. (1986) e Botrel et al. (1987), na Zona da Mata de Minas Gerais. Nesses estudos, a B. ruziziensis, mesmo sob condições de irrigação, produziu apenas $8,5 \%$ do seu rendimento anual de forragem durante o período seco.

Os resultados obtidos, relativos a produção e dis-

TABELA 2. Produção e distribuição estacional de matéria seca (MS) de gramíneas avaliadas na região do sul de Minas Gerais Experimento 1.

\begin{tabular}{lrrrr}
\hline \multirow{2}{*}{ Espécie } & \multicolumn{3}{c}{ Produção de $\mathrm{MS}^{1}(\mathrm{~kg} / \mathrm{ha})$} & \multirow{2}{*}{$\mathrm{A}$} \\
\cline { 2 - 4 } & Seca (A) & Chuvas & Anual (B) & \\
\hline B. brizantha & $3.288 \mathrm{a}$ & $13.091 \mathrm{a}$ & $16.379 \mathrm{a}$ & 20 \\
A. gayanus & $3.118 \mathrm{a}$ & $8.747 \mathrm{c}$ & $11.865 \mathrm{c}$ & 26 \\
B. decumbens & $2.618 \mathrm{a}$ & $11.425 \mathrm{~b}$ & $14.043 \mathrm{~b}$ & 19 \\
B. ruziziensis & $443 \mathrm{~b}$ & $6.067 \mathrm{~d}$ & $6.510 \mathrm{c}$ & 7 \\
B. humidicola & $428 \mathrm{~b}$ & $8.947 \mathrm{c}$ & $9.375 \mathrm{~d}$ & 4 \\
M. minutiflora & $400 \mathrm{~b}$ & $4.643 \mathrm{~cd}$ & $5.043 \mathrm{c}$ & 8 \\
\hline
\end{tabular}

${ }^{1}$ Média de dois anos; as médias na mesma coluna, seguidas pela mesma letra, não diferem entre si pelo teste de Tukey $(\mathrm{P}>0,05)$.

2 Porcentagem da produção anual ocorrida durante o período da seca. 
tribuição de forragem das gramíneas mais promissoras deste trabalho, também foram confirmados em pesquisas conduzidas em outras regiões do Estado de Minas Gerais. Assim, através de estudos de adaptação de forrageiras a solos ácidos e de baixa fertilidade natural, Botrel \& Novelly (1985), Botrel et al. (1987, 1994) indicaram as espécies A. gayanus e B. decumbens para a Região dos Campos das Vertentes e B. brizantha, B. decumbens e A. gayanus para a Zona da Mata de Minas Gerais.

O elevado potencial para produção de forragem, principalmente no período seco, observado com o capim-andropógon pode ser atribuído ao seu sistema radicular profundo, permitindo um melhor aproveitamento da água armazenada no solo, conforme observação de Gomide \& Assad (1990).

Experimento 2 - O capim-setária (Setaria sphacelata cv. Kazungula) apresentou o maior $(\mathrm{P}<0,05)$ potencial para produção de forragem no período seco $(3.588 \mathrm{~kg} / \mathrm{ha})$. Outra gramínea que se destacou pela produção de forragem nessa época do ano foi $P$. maximum cv. Tobiatã, com um rendimento de MS de $2.415 \mathrm{~kg} / \mathrm{ha}$, significativamente inferior à produção do capim-setária, e superior aos das demais gramíneas avaliadas. As outras cultivares de P. maximum, Makueni e Green Panic tiveram produções consideráveis, e semelhantes entre si. A H. altissima, C. nlemfuensis, C. gayana e H. rufa foram as espécies menos produtivas $(\mathrm{P}<0,05)$, e seus rendimentos se assemelharam, e corresponderam, em média, a $13 \%$ da produção alcançada pelo capim-setária (Tabela 3 ).

No período das chuvas, os capins Tobiatã e Setária tiveram rendimentos de 14.133 e $12.888 \mathrm{~kg} / \mathrm{ha}$ de MS, respectivamente. Esses valores foram superiores aos rendimentos do restante das gramíneas avaliadas. As produções de MS dos capins $C$. gayana e $H$. altissima foram as mais baixas, e não diferiram entre si $(\mathrm{P}>0,05)$. As demais gramíneas apresentaram rendimentos variando de 6.563 (cultivar Makueni) a $5.503 \mathrm{~kg} / \mathrm{ha}$ de MS (C. nlemfuensis) (Tabela 3).

Os capins Tobiatã e Setária também se destacaram quanto à produção anual de forragem, que foi em torno de $16.500 \mathrm{~kg} / \mathrm{ha}$ de MS. A menor produção anual de forragem $(\mathrm{P}<0,05)$ foi a do $C$. gayana (2.603 kg/ha de MS). As demais gramíneas apresentaram rendimentos semelhantes, com um valor médio de $6.590 \mathrm{~kg} / \mathrm{ha} /$ ano de MS (Tabela 3).

A melhor distribuição estacional da produção de forragem foi obtida com os capins Setária e Tobiatã, que tiveram 22 e $15 \%$ da produção anual concentrada no período da seca, respectivamente. Por outro lado, o capim-jaraguá ( $H$. rufa), gramínea naturalizada na região, produziu somente $3 \%$ de seu rendimento anual nessa época do ano (Tabela 3).

$\mathrm{O}$ alto potencial para produção de forragem apresentado pelo capim-setária também foi evidenciado em pesquisas conduzidas em diferentes regiões do país (Paulino et al.,1990; Andrade et al., 1991).

TABELA 3. Produção e distribuição estacional de matéria seca (MS) de gramíneas avaliadas na região do sul de Minas Gerais - Experimento 2.

\begin{tabular}{|c|c|c|c|c|}
\hline \multirow[t]{2}{*}{ Espécie } & \multicolumn{3}{|c|}{ Produção de $\mathrm{MS}^{1}$ (kg/ha) } & \multirow{2}{*}{$\frac{\mathrm{A}}{\mathrm{B}} \times 100^{2}$} \\
\hline & $\operatorname{Seca}(A)$ & Chuvas & Anual (B) & \\
\hline S. sphacelata cv. Kazungula & $3.588 \mathrm{a}$ & $12.888 \mathrm{a}$ & $16.476 \mathrm{a}$ & 22 \\
\hline P. maximum cv. Tobiatã & $2.415 b$ & $14.133 \mathrm{a}$ & $16.548 \mathrm{a}$ & 15 \\
\hline P. maximum cv. Green Panic & $847 \mathrm{c}$ & $6.562 b$ & $7.409 \mathrm{~b}$ & 11 \\
\hline P. maximum cv. Makueni & $717 \mathrm{c}$ & $6.563 b$ & $7.280 \mathrm{~b}$ & 10 \\
\hline C. gayana & $308 d$ & $2.295 c$ & $2.603 \mathrm{c}$ & 12 \\
\hline C. nlemfuensis & $280 \mathrm{~d}$ & $5.503 b$ & $5.783 b$ & 5 \\
\hline H. altissima & $280 d$ & $4.633 \mathrm{bc}$ & $4.913 b$ & 6 \\
\hline H. rufa & $210 \mathrm{~d}$ & $7.360 \mathrm{~b}$ & $7.570 \mathrm{~b}$ & 3 \\
\hline
\end{tabular}

${ }^{1}$ Média de dois anos; as médias na mesma coluna, seguidas pela mesma letra, não diferem entre si pelo teste de Tukey $(\mathrm{P}>0,05)$.

2 Porcentagem da produção anual ocorrida durante o período da seca. 
$\mathrm{O}$ alto rendimento forrageiro apresentado pelo capim-setária também foi verificado por Alvim et al. (1986), em estudos conduzidos na Zona da Mata de Minas Gerais, onde essa forrageira foi comparada com várias outras espécies tropicais e subtropicais, sob condições de irrigação no período seco. O capim-setária se destacou tanto pelo rendimento anual de forragem como pelo rendimento na estação seca. Também, nessa região, Alvim et al. (1993) alcançaram elevadas produções de leite em vacas mantidas em regime exclusivo de pasto de capim-setária.

A boa adaptação do capim-setária à região Sul de Minas Gerais certamente está relacionada, entre outras causas, com as condições climáticas locais. Assim, por se tratar de uma espécie subtropical, as baixas temperaturas que ocorrem na região (Tabela 1), não afetam expressivamente o crescimento dessa espécie.

\section{Porcentagem de proteína bruta (PB)}

Experimento 1 - Durante o período da seca, a maior porcentagem de $\mathrm{PB}(\mathrm{P}<0,05)$ foi de $7,6 \%$ alcançado pelo $A$. gayanus. Nas demais gramíneas, a concentração de PB variou de 4,8 a $6,5 \%$, respectivamente, para $B$. humidicola e $B$. brizantha (Tabela 4). Botrel et al. (1994), trabalhando com essas mesmas espé-cies na Região dos Campos das Vertentes de Minas Gerais, obtiveram resultados

TABELA 4. Porcentagem de proteína bruta e de cobertura vegetal do solo de gramíneas forrageiras avaliadas na região do sul de Minas Gerais - Experimento 1.

\begin{tabular}{llcc}
\hline Espécie & \multicolumn{2}{c}{ Proteína bruta $^{1}$} & $\begin{array}{c}\text { Cobertura do } \\
\text { solo }\end{array}$ \\
\cline { 2 - 3 } & Seca $^{2}$ & Chuvas $^{3}$ & \\
\hline A. gayanus & $7,6 \mathrm{a}$ & $11,8 \mathrm{a}$ & 64 \\
B. brizantha & $6,5 \mathrm{ab}$ & $12,3 \mathrm{a}$ & 84 \\
B. decumbens & $5,8 \mathrm{bc}$ & $10,4 \mathrm{ab}$ & 97 \\
B. ruziziensis & $5,7 \mathrm{bc}$ & $12,6 \mathrm{a}$ & 74 \\
M. minutiflora & $5,7 \mathrm{bc}$ & $8,8 \mathrm{~b}$ & 81 \\
B. humidicola & $4,8 \mathrm{c}$ & $8,6 \mathrm{~b}$ & 99 \\
\hline
\end{tabular}

Médias na mesma coluna, seguidas pela mesma letra, não diferem entre si pelo teste de Tukey $(\mathrm{P}>0,05)$

2 Plantas com 70 dias de rebrota.

3 Plantas com 40 dias de rebrota. semelhantes, principalmente no que diz respeito à concentração de PB do A. gayanus. No período das chuvas, os teores de proteína bruta registrados variaram 8,6 a 12,6\% (Tabela 4), valores que não devem comprometer o consumo voluntário pelos animais (Milford \& Minson, 1966), nessa época do ano.

Experimento 2 - Somente as espécies $C$. gayana, $H$. altissima, $C$. nlemfuensis e $H$. rufa apresentaram, durante o período seco, teores de PB abaixo do nível crítico de 7\%, estabelecido por Milford \& Minson (1966). No período das chuvas, o teor de PB das cultivares de $P$. maximum e das espécies $S$. sphacelata e C. gayana foi semelhante (P > 0,05), apresentando valor médio de 13,6\%. Nas demais gramíneas, a concentração média de PB foi de $9,0 \%$, não se observando diferenças significativas entre as mesmas (Tabela 5).

\section{Cobertura do solo}

Pela análise dos dados contidos nas Tabelas 4 e 5, constata-se que, de maneira geral, as gramíneas com hábito de crescimento cespitoso foram menos eficientes na cobertura vegetal do solo, em comparação com as de crescimento prostrado ou decumbentes. Assim, a porcentagem média de cobertura do solo, considerando todas as gramíneas de crescimento cespitoso e prostrado, foi, respectivamente,

TABELA 5. Porcentagem de proteína bruta e de cobertura vegetal do solo de gramíneas forrageiras avaliadas na região do sul de Minas Gerais - Experimento 2.

\begin{tabular}{|c|c|c|c|}
\hline \multirow[t]{2}{*}{ Espécie } & \multicolumn{2}{|c|}{ Proteína bruta $^{1}$} & \multirow{2}{*}{$\begin{array}{c}\text { Cobertura } \\
\text { do solo }\end{array}$} \\
\hline & Seca $^{2}$ & Chuvas $^{3}$ & \\
\hline P. maximum cv. Green Panic & $8,1 \mathrm{a}$ & $13,9 \mathrm{a}$ & 56 \\
\hline P. maximum cv. Makueni & $7,4 \mathrm{a}$ & $13,8 \mathrm{a}$ & 58 \\
\hline S. sphacelata $\mathrm{cv}$. Kazungula & $7,3 \mathrm{a}$ & $13,7 \mathrm{a}$ & 83 \\
\hline P. maximum cv. Tobiatã & $7,0 \mathrm{ab}$ & $13,0 \mathrm{a}$ & 81 \\
\hline H. altissima & $6,7 \mathrm{abc}$ & $9,6 b$ & 89 \\
\hline C. gayana & $6,3 a b c$ & $13,5 \mathrm{a}$ & 52 \\
\hline C. nlemfuensis & $5,5 \mathrm{bc}$ & $8,6 \mathrm{~b}$ & 96 \\
\hline H. rufa & $5,1 \mathrm{c}$ & $9,0 \mathrm{~b}$ & 57 \\
\hline
\end{tabular}

Pesq. agropec. bras., Brasília, v.34, n.4, p.683-689, abr. 1999 
66 e $84 \%$. Esses resultados são importantes por ocasião da escolha da espécie forrageira a ser utilizada para a formação de pastagens em áreas montanhosas, onde há altos riscos de erosão, devendo, elas, cobrir rapidamente o solo. Por outro lado, vale ressaltar o comportamento dos capins Setária e Tobiatã, que proporcionaram ao solo uma cobertura vegetal de 83 e $81 \%$, respectivamente, mesmo possuindo hábito de crescimento ereto.

Por comparação dos resultados obtidos nos experimentos 1 e 2 , verifica-se que a $B$. brizantha avaliada em sistema de baixo insumo apresentou um potencial forrageiro semelhante ao dos capins Setária e Tobiatã, que foram avaliados em sistema mais intensivo de produção de forragem. Esses resultados sugerem a realização de estudos com a $B$. brizantha, visando sua utilização em sistemas intensivos de produção de leite à pasto.

\section{CONCLUSÕES}

1. As espécies Setaria sphacelata cv. Kazungula, Panicum maximum cv. Tobiatã e Brachiaria brizantha são as mais indicadas para uso em sistemas mais intensivos de produção animal a pasto, na região Sul de Minas Gerais.

2. As espécies Brachiaria brizantha, Andropogon gayanus e Brachiaria decumbens são as mais indicadas para formação de pastagens em solos ácidos e de baixa fertilidade na região Sul de Minas Gerais.

\section{REFERÊNCIAS}

ALVIM, M.J.; BOTREL, M. de A.; NOVELLY, P.E. Produção de gramíneas tropicais e temperadas, irrigadas na época da seca. Revista da Sociedade Brasileira de Zootecnia, Viçosa, MG, v.15, n.5, p.384-392, 1986.

ALVIM, M.J.; MARTINS, C.E.; BOTREL, M. de A.; JACOB, M.A.M. Efeito da irrigação e da integração entre pastagens de setária e de azevém anual sobre a produção de leite. Pesquisa Agropecuária Brasileira, Brasília, v.28, n.4, p.545-554, abr.1993.

ANDRADE, J.B.; PEDREIRA, J.V.; HENRIQUE, W. Comparação de três capins da espécie Panicum maximum Jacq. (Colonião, Tobiatã e K - 1878) sob dois níveis de adubação nitrogenada. Boletim da Industria Animal, Nova Odessa, v.48, n.2, p.77-82, 1991.

ASSIS, A.G. de. Alimentação de vacas leiteiras. Coronel Pacheco: Embrapa-CNPGL, 1982. 43p. (Embrapa-CNPGL. Documentos, 7).

ASSIS, A.G. de. Sistema de alimentação de vacas em produção. Coronel Pacheco: Embrapa-CNPGL, 1986. 54p. (Embrapa-CNPGL. Documentos, 26).

ASSOCIATION OF OFFICIAL AGRICULTURE CHEMISTS (Washington, DC). Official methods of analysis. 11.ed. Washington, DC, 1970. 1015p.

BOTREL, M. de A.; ALVIM, M.J.; MOZZER, O.L. Avaliação agronômica de gramíneas forrageiras sob pastejo. Pesquisa Agropecuária Brasileira, Brasília, v.22, n.9/10, p.1019-1025, set./out. 1987.

BOTREL, M. de A.; ALVIM, M.J.; XAVIER, D.F.; SALVATI, J.A. Avaliação de forrageiras em dois municípios na região do Campo das Vertentes de Minas Gerais. Revista da Sociedade Brasileira de Zootecnia, Viçosa, v.23, n.2, p.189-196, 1994.

BOTREL, M. de A.; NOVELLY, P.E. Avaliação de gramíneas e leguminosas forrageiras sob pastejo em duas regiões fisiográficas do estado de Minas Gerais. Coronel Pacheco: Embrapa-CNPGL, 1985. 21p. (Embrapa-CNPGL. Boletim de Pesquisa, 12).

BROWN, D. Methods of surveving and measuring vegetation. Hurley: Commonwealth Bureau Pastures Fields Crop, 1954. 22 p. (Bulletin, 42).

GOMIDE, C.C.C.; ASSAD, E. D. Avaliação da distribuição do Andropogon gayanus cv. Planaltina utilizando imagens de satélite TM. Landsat em áreas de cerrado. Pasturas tropicales, Cali, v.12, n.3, p.2-6, 1990

MARTINEZ, R.O. Concentrate feeding and milk production with tropical pastures. Cuban Journal of Agricultural Science, La Habana, v.15, n.1, p.121-132, 1981.

MILFORD, R.; MINSON, D.J. Intake os tropical pastures species. In: INTERNATIONAL GRASSLAND CONGRESS, 11., 1966, São Paulo. Proceedings... São Paulo: Secretaria de Agricultura-Departamento da Produção Animal, 1966. p. 815-822.

PAULINO, V.T.; PACOLA, L.J.; BUFARAH, G. Competição de plantas forrageiras cultivadas num solo Latossolo Roxo de Sertãozinho, SP. Boletim da Indústria Animal, Nova Odessa, v.47, n.2, p.133-139, 1990. 
PEREIRA, J.P.; FONSECA, D.M. Região Sul de Minas. Informe Agropecuário, Belo Horizonte, v.6, n.70, p.22-26, 1990.

STOBBS, T.H. Milk production per cow and per hectare from tropical pastures (milk production from tropical pastures). In: SEMINARIO INTERNACIONAL DE GANADERIA TROPICAL, 5., 1976, Memória... Acapulco: Secretaría de Agricultura y Ganaderia, 1976. p.129-179.

VICENTE-CHANDLER, J.; CARO COSTA, R.; ABRUA, F.; SILVA, F. Producción y utilización intensiva de las forrageras em Puerto Rico. Rio Piedras: Universidade de Puerto Rico, Estación Experimental Agrícola, 1983.229p. (Universidade de Puerto Rico, Estación Experimental Agrícola. Boletín, 271).

VIEIRA, A. Gramíneas forrageiras . Revista dos Criadores, São Paulo, v.64, n.777, p.26-37, 1994.

ZOCCAL, R. Leite em números. Coronel Pacheco: Embrapa-CNPGL/Belo Horizonte: FAEMG, 1994. $131 \mathrm{p}$ 